\title{
Enhancing information research and learning skills through e-learning: the case of Monash University Library
}

\author{
Sibusisiwe K. Mgquba ${ }^{1}$ and Peter G. Underwood ${ }^{2}$ \\ sibusisiwe.mgquba@monash.edu ORCID: orcid.org/0000-0001-8413-8418 \\ pgunderwood@wol.co.za ORCID: orcid.org/0000-0002-9618-5032
}

\begin{abstract}
Received: 20 October 2015
Accepted: 27 January 2016

This paper focuses on the use of e-learning technologies for the purposes of enhancing information research and learning skills (IRLS) at Monash University Library. The objective of the research was to establish how Monash University Library integrates its vast resources and services through the medium of e-learning; what role Librarians and Learning Skills Advisers play in teaching and learning through e-learning; what measures were used to assess the effectiveness of e-learning in IRLS; what challenges Librarians and Learning Skills Advisers encountered in creating e-learning content for IRLS; and lastly, what the strengths and limitations of e-learning in the provision of IRLS are. The qualitative method was used as a research design and the population group consisted of Subject Librarians and Learning Skills Advisers from the Australian and South African campuses of Monash University. A questionnaire was used as the method of data collection.
\end{abstract}

Keywords: E-learning, information research, information literacy, learning skills, Monash University Library

\section{Introduction and background}

Technology enhanced learning (e-learning) has become one of the dominant modes of teaching and learning in higher education today. Indeed, it seems that no higher education institution can survive without embracing the new educational technologies that have come to define teaching and learning in the information and knowledge era. Educational technologies have become one of the main methods of delivering teaching and learning content. Rooted in established pedagogical foundations, e-learning adopts the constructivist approach to teaching and learning which attributes the construction of knowledge to learner experiences. Thus, learners construct their own understanding and knowledge through interaction with others. As universities adopt the e-learning approach, their libraries are forced to find ways to deliver their content in ways that the new generation of student prefers and on platforms where it interacts.

The NMC Horizon Report, which is a series of reports that predicts the major influential technologies that are likely to impact on research, teaching and learning in higher education, is one of the most useful publications for understanding the impact emerging technologies have on higher education. The report notes that concepts like 'open content', 'open data' and 'open resources', along with notions of transparency and easy access to data and information are becoming essential (Johnson et al. 2013).

Freeman (2007) asserts that libraries must experiment with new ways of supporting the academic community and must be flexible in order to accommodate evolving information technologies. Monash University Library (MUL) has risen to the challenge by making e-learning one of its strategic priorities in support of research, teaching and learning.

\section{Problem and purpose of the study}

Libraries and librarians are faced with a rapidly evolving higher education landscape, influenced by equally rapidly evolving information and communication technologies (ICTs). Traditional library science degrees and related qualifications have not quite equipped librarians and information professionals for handling these changes, nor has succession planning prepared librarians adequately for them.

ICTs and the internet bring with them a plethora of unstructured, unevaluated information. The availability and accessibility of this vast amount of information means that information literacy (IL) has never been as relevant as it is right now. As Ward (2010) puts it, we, as a profession accept that the increasing volume of information is only of value to an academic community when it is employed in a meaningful way within the process of learning. Acquiring, selecting, disseminating, evaluating and using information are skills that are common to librarians. By using these skills for rigorous IL teaching and training, librarians can still offer valuable services in their academic environments.

Walker, Huddlestone and Pullen (2010) argue that the rapid rise in fast, mass communication has reached the point where we must learn to use technology efficiently and effectively in order to live, learn and work successfully. Linking lifelong learning and IL with e-learning is one way in which some libraries are trying to deliver their services and remain relevant in the information and knowledge era. Authors like Ward (2010), Andretta (2005), Joint (2005), Hadengue (2005)

1. Sibusisiwe Mgquba is an M.IT graduate of the University of Pretoria

2. Peter G. Underwood is an M.IT supervisor for the University of Pretoria 
and Secker (2004) are some of several authors who have argued for the link between IL and e-learning. They maintain that IL should play the central role in any e-learning initiative and that, in this complex learning environment, e-learning should be supported by solid IL frameworks. This research, therefore, looked at how MUL has used e-learning technologies to enhance IL, or Information Research and Learning Skills (IRLS) as it is referred to at MUL.

The study aimed to address the following research question:

- How has Monash University Library used e-learning to enhance IRLS?

The following sub-questions further informed the study;

- What role have Librarians and Learning Skills Advisers played in teaching and learning through e-learning at MUL?

- What measures are used to assess the effectiveness of e-learning in IRLS?

- What challenges do Librarians and Learning Skills Advisers encounter in creating e-learning content for IRLS?

- What are the strengths and limitations of e-learning in the provision of IRLS?

\section{Review of literature}

There is considerable literature on the subject of e-learning, especially pertaining to higher education. The globalisation of higher education is widely covered in academic literature and e-learning as such is a major focus of these discussions. This review process seeks to determine the historical development of the study of e-learning within higher education. It focuses on e-learning specifically, pertaining to higher education, academic libraries and especially its use in IL.

\subsection{E-learning: history and background}

Catherall (2005) defines e-learning as any technology allowing for the delivery of learning resources or communication between tutor and student. Meredith and Burkle (2006) define e-learning as learning facilitated by internet and World Wide Web technologies that creates connectivity between people and information, and creates opportunities for social learning approaches. Definitions of e-learning allude to a type of learning that is supported, enhanced or facilitated by technology and the internet. Harasim (2006) argues that the genesis of e-learning as based on human collaboration in knowledge work and innovation can be traced to the development of network communication in the late 1960s, and the invention of e-mail and computer conferencing over packet-switched networks in 1971. Nicholson (2007) however, points out that in the history of e-learning, it is important to bear in mind that no single evolutionary tree and no single agreedupon definition of e-learning exists. He goes on to say that, since the 1960s, e-learning has evolved in different ways in many spheres such as business, education, training, as well as the military. Thus, the form and shape of e-learning might have changed over time, as well as with the introduction of new digital technologies, but it must be understood within the context in which it is applied.

\subsection{E-learning in higher education}

Faced with dwindling budgets and escalating costs, educational institutions are being forced to cut expenditure and find innovative ways to provide high quality services at lower rates. Herrington (2006) argues that the most powerful use of technology in higher education is where technologies are used as tools in authentic learning environments. Laurillard (2006) asserts that e-learning is important in higher education because the use of ICTs and interactive technologies support many different types of capabilities; for each of these capabilities there is a learning application that could be exploited in higher education.

For the time being, e-learning seems to be a worthwhile strategic move but it is not without pitfalls. E-learning proponents are often accused of failing to recognise the significance of these pitfalls in that there has been very little or no research done on whether the 'learning' in 'e-learning' actually occurs. Several authors such as Njenga and Fourie (2010), Guri-Rosenblit (2005) and Gandolfo (1998) have warned that the discourse on new technologies, especially in the academic and corporate arena, fails to bridge the gap between rhetoric in literature describing the sweeping effects of digital technologies on educational environments and their actual implementation. As Guri-Rosenblit (2005) puts it, often discourse on new technologies suffers from "The Tower of Babel Syndrome" - confusing language and misleading conclusions, emanating from the fact that people refer to different functions and roles using the same terms. She argues that the language used to depict these learning environments is often blurred and confusing. Njenga and Fourie (2010) concur with Guri-Rosenblit (2005) when they say that there is no clear distinction between teaching with, and teaching about, technology.

\subsection{E-learning and academic libraries}

Traditionally, libraries have played the role of custodian of print and other resources and have gradually moved to electronic resource provision and management. This move has been the result of new technological advancements, such as virtual learning or learning management systems, being introduced into higher education. Libraries therefore find themselves in a position where they have to play a bigger role in teaching, learning and research in order to remain relevant to their academic constituencies. According to the OCLC E-learning Task Force (2003: 6), "e-learning integration offers libraries a powerful medium for reaching faculty and students directly as they engage in teaching, learning, 
research and outreach". Consequently, this integration helps the library to reach both faculty and those students who no longer make physical use of the library by providing a web-based and enriched service for their information needs. Sen (2009: 177) believes that, "academic libraries need to apply appropriate communication technologies in support of elearning and e-research by providing seamless access to electronic resources and services". Sharifabadi (2006) reports that one of the challenges libraries face is the widespread availability of free information on the web which has serious implications for education programmes, as well as for understanding library users' behaviour. One of the solutions to this challenge, as suggested by Lippincott (2002), is that libraries should support e-learning designed to meet the needs of learners, in both individual and collaborative settings.

\subsection{Applying e-learning to IL}

The American Library Association (1989) defines information literacy as the ability to recognise when information is needed and having the ability to locate, evaluate, and use effectively the required information. A person who is information literate is one who has learned how to learn because he/she knows how information is organised, how to find it and how to use it in such a way that others can learn from him/her. According to the International Guidelines on Information Literacy compiled by the Information Literacy Section of the International Federation of Library Associations (IFLA), there are several terms that contribute to the concept of IL which, when broken down, relate to different types of skills, levels, and categories of learning, among other aptitudes (Lau 2006). In this context, IL focuses on information use rather than on bibliographic skills: that is, students must develop information competencies to become effective learners. The constructivist based approach of learning in $\mathrm{IL}$ focuses on students engaging with information in order to solve a problem and thereby creating new understanding by active investigation and thought, instead of memorising facts presented in class (Lau 2006).

\section{Research methods}

E-learning is underpinned by pedagogical theories (Mayes \& de Freitas 2004) which take a constructivist worldview. The researchers wished to match this worldview with a method of investigation: accordingly, the qualitative approach was selected as the research framework. In qualitative research design, the researcher seeks to establish the meaning of a phenomenon from the views of participants (Creswell 2009). This type of research is characterised by a narrative design approach, participatory worldview and open-ended interviewing. Such an approach can only yield an imperfect understanding unless it is possible to improve understanding by gathering views from participants and other sources in order to verify (triangulate) them.

Case studies are commonly used when a researcher wishes to gain an understanding of meaning within the context of a system that has clear boundaries (Yin 2012). Research into the question, "How has the MUL used e-learning to enhance Information Research and Learning Skills?" is congruent with the case study method, in that the problem to be studied is bounded within MUL, while the activity of e-learning is also clearly circumscribed. The effect to be investigated (skills enhancement) is also clear and the area of skills (Information Research and Learning) is also clearly identified. For each aspect, the decision to include or exclude an observation can be made based upon whether it falls within or outside of the problem space.

A combination of questionnaire and observation was selected as the most appropriate research instruments. This decision was driven by the geographically-dispersed nature of the population to be studied.

The population for the study comprised Subject Librarians, Learning Skills Advisors (LSA), E-learning Co-ordinators and Information Research and Learning Skills Managers at MUL. These groups were targeted because of their direct involvement in the formulation of policy, content creation, and instruction of information research and learning skills using e-learning platforms. MUL has more than two hundred staff in these categories situated on ten campuses. Because of geographical and other constraints, it was decided to limit the survey to a sample group of thirty-five. The sample consisted of fifteen Subject Librarians, fifteen Learning Skills Advisers and five Information Research and Learning Skills Managers and e-Learning Co-ordinators. The latter (Managers and E-learning Co-ordinators) were represented under the category 'other' in the questionnaire because Managers, although involved in driving the strategic directions of e-learning in the Library, do not directly create content. On the other hand, E-learning Co-ordinators, together with SLs and LSAs, are directly responsible for the creation, editing and teaching of e-learning. Their expertise therefore lies in content creation and instructional design, while the Subject Librarians and Learning Skills Advisors bring pedagogical, research and learning skills to the table.

The response was disappointing: seven Subject Librarians responded to the questionnaire, as did six Learning Skills Advisers and three Managers, giving an overall response of sixteen, or $45.7 \%$. Timing and the distance between the researchers and colleagues overseas may be adduced as the reasons for the low response. The rich detail provided in the comments by the respondents yielded valuable insight into the management of e-learning, but any attempt at generalisation from the results has been avoided because of the lack of representativeness of the responses.

\section{Findings}

The section that follows presents the findings of the study. 


\subsection{Expertise in creating pedagogically effective e-learning content}

The definitions of e-learning supplied by respondents showed a clear understanding of the pedagogical principles that underlie e-learning in the educational context. Therefore, staff may be considered cognisant of the link between e-learning content creation and how it fits within the broader educational objectives of Monash University. However, the findings also revealed that the knowledge and expertise considered necessary in e-learning content creation was quite diverse. Most respondents felt that they didn't possess enough of the skills necessary to create such content. Linking e-learning to sound pedagogy is the basis of creating effective content, but that is not quite enough. A sound knowledge of the fundamental principles of teaching and learning, educational theories, a teaching qualification, IT skills, instructional/educational design, and curriculum design are some of the skills and expertise the respondents felt they needed.

Although some respondents had some experience of or had attended a course in e-learning content creation, there was a need to continue growing skills in this area. Only $25 \%$ of the population group felt that they had advanced skills in e-learning content creation. This percentage indicates a clear need for continuous training in this area as it evolves, as the curriculum changes, and as student needs change. One respondent commented, "I learn through trial and error. I find that most e-learning courses are often behind the times and far too basic for my needs". This statement is an indication that e-learning technologies change rapidly and staff have to keep abreast with new developments if they are to deliver effective e-learning teaching and learning content.

\subsection{E-learning in/for Information Research and Learning Skills}

The main aim of e-learning initiatives at MUL is to enhance IRLS. The research question in relation to this aim was: "How has MUL used e-learning to enhance IRLS"? The findings revealed that Librarians and Learning Skills Advisers have actively and successfully created a substantial number of e-learning objects using different platforms and for different tasks with differing learning objectives. Some of these objects have included quizzes and courses on Moodle (a learning management system designed for online learning), instructional videos embedded on Moodle, and online tutorials for different tasks. In addition, these authors observed that the development of the Monash Library e-Learning Objects Repository points to an active engagement with e-learning in the Library. The vast array of e-learning objects in the repository is a clear indication of how involved Librarians and Learning Skills Advisers are in content creation.

The need for the creation of different types of content was attributed to various reasons ranging from lack of contact time with students, requests from academics for such resources, and minimising the number of contact workshops for teaching such skills. One of the respondents said that these resources can be used as "backup" by students who need extra help. Another respondent highlighted the importance of collaborating with academics when creating these modules in order to blend content that is relevant to students.

The types of e-learning software that were used to create IRLS modules were Moodle and other design tools for creating e-learning content, namely Adobe Presenter, Articulate Storyline and Captivate. Moodle was shown to be the preferred platform as $81 \%$ of respondents reported that they used it the most. Captivate was another preferred platform for creating e-learning content. It is one of the platforms on which MUL conducted focused training of staff in 2012 when MUL undertook to train staff on new e-learning technologies. The main aim of the course was to empower staff with knowledge and skills to create e-learning tutorials that are aligned with the learning objectives of Monash University. In their paper on developing staff capabilities for online learning at Monash University Library, Smith and Yates (2012: 25) reported that staff evaluation and feedback after the course indicated that there was a need for "further investigation into how other libraries in Australia and around the world address staff training of complex subject matter and skills and in geographically dispersed working communities". Furthermore, "the course should be about much more than using a piece of software but also about the e-learning development process" (Smith and Yates 2012: 25).

\subsection{Effectiveness of e-learning in IRLS}

Evaluating the effectiveness of IRLS or IL is perhaps the most difficult part of library and information instruction. Now, elearning in IRLS provides an even more complex problem for librarians as there is often no face-to-face interaction by which to measure the student's response. Even in a workshop or face-to-face environment, there is no certainty that the skills that students have learned will translate into better academic performance.

The research revealed, firstly, that the Library uses many platforms and initiatives to promote e-learning objects. The respondents mentioned Moodle (course-specific Moodle sites) as the most effective platform to promote e-learning objects, especially if embedded with a specific task or objective that the students are working towards. Orientation, class contact sessions, embedding in subject guides and individual consultations are some of the other platforms respondents said they used for raising awareness. Academic staff are seen to be the best people to promote e-learning objects, as students have more contact time with them and generally take what their lecturers say more seriously.

The existence of these initiatives does not translate into an assessment of how effective they are in teaching and learning. Usage statistics of the e-learning objects, lecturer feedback (in terms of student performance in assignments), informal student feedback and evaluation forms are some of the assessment measures used by respondents. Some respondents, however, gave an indication that questions around assessment are difficult to answer. One respondent articulated it this way: "That's a difficult one! I suppose if lecturers report an improvement in student's assessment tasks? Some of the modules do collect usage stats as well but that doesn't always mean effectiveness, right?"

Judging from this response, the researchers might conclude that assessing the effectiveness of e-learning in IRLS is one area where a concerted effort still needs to be made. 


\subsection{Challenges in e-learning content creation}

The study indicated that most of the challenges encountered in e-learning content creation had to do with time constraints, lack of skills and the rapid developments in e-learning technologies with which respondents felt they did not have time to keep up. Maintaining the balance between being a Librarian or Learning Skills Adviser and a content creator was seen as a challenge. Respondents felt that content creation took them away from their main responsibilities. Others said that they were 'old school' and preferred interacting in person with students. As one respondent put it, "It's not always easy to create online content for the reason that you can't put a face to what you're trying to communicate. Students also cannot ask questions or ask you to clarify something they don't understand, as they would in a class setting".

E-learning content creation requires dedicated time and respondents felt that this was time they did not have as they had more pressing responsibilities. Time pressures and lack of skills therefore came up as the biggest challenge in elearning content creation.

\subsection{Strengths and limitations of e-learning in the provision of IRLS}

As reported elsewhere in this paper, the author wished to establish whether MUL staff embarked on e-learning initiatives because it was part of the Library's strategic priorities or if they actually believed in what it was trying to achieve. As creators of content, these authors felt it was important for respondents to put themselves in the student's shoes and assess e-learning initiatives as a student would. That way, they could look objectively at e-learning for IRLS, not as creators but as receivers of the content. It is important to address these challenges in order to improve on best practices and to address issues that might otherwise not be evident to Library management. Where there are strengths, it is important to take note of them and use these to improve in other areas.

The research draws attention to some of the strengths of e-learning in IRLS, such as that e-learning allows for a wider reach of services to students, anywhere and at any time. There is no limit to how many times a student can interact with a module: all content is repeatable. E-learning also accommodates independent learning styles. It saves Librarians and Learning Skills Advisers time as there is no repetition of tasks done in class, for example. One respondent explained the learning process involved in e-learning as follows: "The more we learn about e-learning, the closer we are to understanding how to explain simply and efficiently the process of learning and research".

E-learning also encourages independent critical thinking in learners by giving them the responsibility for learning. It also reduces training costs and increases the scope of offerings. Lastly, e-learning allows for a quick response to constant change and rapid product innovations.

There were also indications of limitations of e-learning in IRLS. E-learning does not cater for all learning styles. Some students lack the IT skills needed for effective interaction with e-learning content. There is not enough awareness of the existence of e-learning resources; most students don't know that they exist. Some respondents felt that the lack of human interaction with Librarians and Learning Skills Advisers made staff feel redundant. It was reported that the effectiveness of e-learning in IRLS was difficult to measure. Although usage statistics and student feedback were seen as measures, some respondents felt that these could not be used to determine effectiveness. Another frequently-mentioned limitation was the lack of instructional design skills by staff. The respondents felt that lack of skills resulted in poor quality content. One respondent stated that e-learning modules were not cross-platform friendly: they could not be used on mobile devices, for example, a big limitation in an environment where learners use a variety of devices, especially mobile devices. The idea behind e-learning is that resources and services are available anywhere and anytime. Therefore, elearning technologies should be compatible with varying types of ICTs.

One of the questions asked in the study was which type of e-learning model respondents preferred: standalone modules, tutorials or simulations; online collaborative learning; or blended learning. Surprisingly, $75 \%$ of respondents said they preferred the blended learning model. Some of the reasons cited for this preference were that blended learning caters for both learning styles. A mix of traditional and online teaching and learning methods was preferred to just one learning models. Others felt that the type of e-learning model used should be dictated by the desired learning outcomes of the task or activity at hand. There is no 'one size fits all' solution in the e-learning context and therefore content creators should be well versed in the learning objectives of the tasks for which they create content. One respondent articulated this challenge as follows: "E-learning is a tool. Its weaknesses and strengths come from the way in which people use it. An uncritical approach to e-learning creates false expectations. E-learning in itself is not a solution".

\section{Discussion and conclusion}

The findings of this study revealed that e-learning in IRLS is changing the way the Monash University Library provides its services to the university. There has been considerable success in this endeavour but there are still challenges. What is evident from the research is that there has not been a thorough evaluation of the effectiveness of e-learning in IRLS. There is no clear indication of how these activities translate to better learning outcomes. Again, usage statistics or student enrolment on e-learning Moodle units cannot be used as a measure of the effectiveness of e-learning in IRLS. As with information literacy training, the important measure lies in the assessment of student academic performance and the consequent determination of its effectiveness, not in the number of students who attend IL training sessions. This kind of assessment becomes more complex in an e-learning environment.

E-learning will continue to shape the academic landscape, and academic libraries have to play a pivotal role in delivering their services in the same medium. What is pertinent is that e-learning must not occur for its own sake: an effort needs to be made to ensure that there is a real value added to academic teaching and learning. 
This study suggests, firstly, that a conceptual model to measure the effectiveness of e-learning is essential. Whilst the effectiveness of e-learning in teaching and learning still remains debatable in e-learning research and literature, Leung (2003: 124) says that, "the important goal of e-learning is that it should be equivalent to or better than learning provided through other delivery modes, such as the traditional face-to-face and classroom-based methods of instruction". The difficult task of evaluating learning is compounded in e-learning. As the study shows, many respondents were unable to provide a satisfactory account of the effectiveness of e-learning in IRLS.

MacGregor and Turner (2009) argue that, while some studies support the view that there is no evidence for the contention that e-learning is more effective than traditional teaching methods, others found e-learning to be more effective. They contend that there is a need for greater emphasis on empirical research and that researchers in this field need to be more cognisant of the multifarious variables that influence e-learning effectiveness. They state that these variables include "level of learner control; social interactivity; learning styles; e-learning system design; properties of learning objects used; system or interface usability; ICT and information literacy skills; and the manner or degree to which information is managed with the e-learning environment" (MacGregor \& Turner 2009: 163).

What is evident in this study is that there is a theoretical understanding of e-learning based on sound pedagogical foundations. The focus seems to have been biased towards content creation and, up until the date on which this research was concluded, there does not appear to have been a focus on evaluating these efforts. These authors would therefore suggest that a thorough assessment into the effectiveness of e-learning in IRLS be conducted. There are many proposed models for evaluating e-learning effectiveness but very few fit within the context of academic libraries and IL. Therefore, MUL should develop its own assessment model that is aligned with the curriculum and the Research Skills Development Framework. That way, when Librarians and Learning Skills Advisers create e-learning content, they have access to a conceptual framework that guides them. The variables which MacGregor and Turner (2009) mentioned above could be used as a guide as to what to include in such a model.

A second finding is that the introduction of librarians specialising in e-learning is essential. One of the major issues Librarians and Learning Skills Advisers mentioned in this study is that they had little time to create e-learning content. They had many other responsibilities and producing quality content requires a considerable amount of time. Coupled with expertise, which many felt they did not have, it is suggested that MUL introduces a new role of E-learning Librarian. The E-learning Librarian would work closely with the E-learning Coordinator or Instructional Designer, but would contribute the IRLS expertise needed to create content. In that way, only librarians who are passionate about this field would apply and they would then be responsible for training, content creation and most of the duties related to e-learning in IRLS. The Elearning Librarian could also encourage consideration of the role librarians can play in course-integrated instruction and curriculum planning, as these are areas which require hands-on involvement by the Library to produce more effective elearning content for improved teaching and learning. The role would also foster a much more collaborative relationship between academics and the Library.

Coupled with the above, continuous training and skilling of staff is required. The rapid changes in ICTs in higher education require an intense focus on the skilling and re-skilling of staff. Libraries, especially, have become hubs of information and technology and many librarians are not fully equipped to deal with these new developments. New fields such as data management, e-learning, blended learning and e-resources have emerged and these require that librarians engage in teaching and learning in ways that previously were not their domain of expertise. Therefore, there is a constant need to make training an integral part of their functions.

Technologies change rapidly, and as one respondent remarked, knowledge can very easily become outdated in this field. As Ward (2010) argues, the convergence of e-learning technologies, new practices in the broader teaching world and the increasing volume of information and information literacy, have all reaffirmed the academic library as central to teaching and learning. If the MUL is to continue to exploit technology to improve learning outcomes and remain central in the education process, it has to put a concerted effort into staff training and skilling.

\section{References}

American Library Association. 1989. American Library Association Presidential Committee on Information Literacy: final report. Chicago: ALA. [Online]. http://www.ala.org/acrl/publications/whitepapers/presidential (18 January 2015 ).

Andretta, S. 2005. From prescribed reading to the excitement or the burden of choice. Information literacy: foundation of e-learning. Aslib Proceedings, 57(2): 181-190.

Catherall, P. 2005. Delivering e-learning for information services in higher education. Oxford: Chandos.

Creswell, J. W. 2009. Research design: qualitative, quantitative, and mixed methods approach. Los Angeles: Sage.

Freeman, G.T. 2007. The library as place: changes in learning patterns, collections, technology and use. Washington: Council on Library and Information Resources. (CLIR series: 129).

Gandolfo, A. 1998. Brave new world? The challenge of technology to time-honoured pedagogies and traditional structures. New Directions for Teaching and Learning, 76: 23-38.

Guri-Rosenblit, S. 2005. Eight paradoxes in the implementation process of e-learning in higher education. Higher Education Policy, 18(1): 5-29.

Hadengue, V. 2005. E-learning for information literacy: a case study. Library Review, 54(1): 36-46.

Harasim, L. 2006. A history of e-learning: shift happened. In The international handbook of virtual learning environments. J. Weiss, J. Nolan, J. Hunsinger and P. Trifonas, Eds. Dordrecht: Springer. 59-94. 
Herrington, J. 2006. Authentic e-learning in higher education: design principles for authentic learning environments and tasks. World Conference on E-Learning in Corporate, Government, Healthcare, and Higher Education. T. Reeves and S. Yamashita, Eds. Chesapeake, VA: Association for the Advancement of Computing in Education (AACE). 3164-3173.

Johnson, L., Adams Becker, S., Cummins, M., Estrada, V., Freeman, A. and Ludgate, H. 2013. NMC Horizon report: 2013 Higher Education edition. Austin, Texas: The New Media Consortium.

Joint, N. 2005. eLiteracy or information literacy: which concept should we prefer? Library Review, 54(9): 505-507.

Lau, J. 2006. Guidelines on information literacy for lifelong learning. The Hague: IFLA. [Online]. http://www.ifla.org/publications/guidelines-on-information-literacy-for-lifelong-learning (8 October 2015).

Laurillard, D. 2006. E-learning in higher education. In Changing higher education: the development of learning and teaching. P. Ashwin, Ed. Oxford: Routledge. 71-84.

Leung, H. K. 2003. Evaluating the effectiveness of e-learning. Computer Science Education, 13(2): $123-136$.

Lippincott, J. K. 2002. Developing collaborative relationships: librarians, students, and faculty creating learning communities. College \& Research Libraries News, 63(3): 190-192.

MacGregor, G. and Turner, J. 2009. Revisiting e-learning effectiveness: proposing a conceptual model. Interactive Technology and Smart Education, 6(3): 156-172.

Mayes, T. and de Freitas, S. 2004. Review of e-learning theories, frameworks and models. London: Joint Information Systems Committee. [Online]. http://www.jisc.ac.uk/whatwedo/programmes/elearningpedagogy/outcomes.aspx (26 January 2016).

Meredith, S. and Burkle, M. 2006. E-learning: encouraging international perspectives. A Mexican-UK comparative case study analysis. International Journal on E-learning, 5(4): 469-491.

Nicholson, P. 2007. A history of e-learning: echoes of the pioneers. In Computers and education: e-learning from theory to practice. B. Fernández-Manjón, J. M. Sánchez-Pérez, J.A. Gómez-Pulido, M.A. Vega-Rodríguez and J. BravoRodríguez, Eds. Dordrecht, The Netherlands: Springer. 1-11.

Njenga, J. K. and Fourie, L. C. H. 2010. The myths about e-learning in higher education. British Journal of Educational Technology, 41(2): 199-212.

OCLC E-learning Task Force 2003. Libraries and the enhancement of e-learning. Dublin, Ohio: OCLC. [Online]. http://www5.oclc.org/downloads/community/elearning.pdf (Accessed 8 October 2015).

Secker, J. 2004. E-learning and information literacy. In Electronic resources in the virtual learning environment: a guide for librarians. J. Secker, Ed. Oxford: Chandos. 53-74. [Online]. http://eprints.Ise.ac.uk/4884/1/Elearning_and_information_literacy_\%28LSERO\%29.pdf (8 October 2015).

Sen, S. 2009. Academic libraries in e-teaching and e-learning. Paper presented at the International Conference on Academic Libraries (ICAL). 5-8 October. Delhi University, India. [Online]. http://crl.du.ac.in/ical09/papers/index_files/ical-29_46_135_1_LE.pdf (20 April 2015).

Sharifabadi, S. R. 2006. How digital libraries can support e-learning. Electronic Library, 24(3): 389-401.

Smith, L. and Yates, S. 2012. Online learning: eM-powering eFutures through developing staff capability at Monash University Library. Paper presented at VALA2012 16th Biennial Conference. 6-9 February. Melbourne, Australia. [Online]. http://www.vala.org.au/direct-download/vala2012-proceedings/436-vala2012-session-13-smith-paper/file (19 April 2015).

Walker, A., Huddlestone, B. and Pullen, D. L. 2010. An overview of technology in society. Hershey, PA: IGI Global.

Ward, J. 2010. Applying e-learning technologies to library information literacy instruction. In Critical design and effective tools for e-learning in higher education: theory into practice. R. Donnelly, J. Harvey and K. O'Rourke, Eds. Hershey, PA: Information Science Reference. 693-709.

Yin, R. K. 2012. Applications of case study research. Los Angeles: Sage. 